For the full versions of these articles see bmj.com

EDITORIALS

\title{
Sexual health in adolescents
}

\section{"Saved sex" and parental involvement are key to improving outcomes}

\section{RESEARCH p133}

\section{Trevor Stammers}

lecturer in healthcare ethics

St Mary's University College,

Twickenham, London TW1 4SX

tgstammers@doctors.org.uk

Competing interests:

TS is a trustee of Family Education

Trust and Challenge Teams UK;

both charities provide abstinence

centred sex education packages to

secondary schools in the UK. He is

also a (volunteer) web doctor for

Love for Life, the largest provider of

abstinence centred sex education

to schools in Northern Ireland, and

did paid consultation work for them

in the past.

BMJ 2007;334:103-4

doi: 10.1136/bmj.39087.374653.BE
Despite increasing provision of school sex education, teenage sexual health in the United Kingdom is in overall decline, with increasing rates of terminations and sexually transmitted infections in under 18 s outweighing recent modest reductions in conception rates in this age group. ${ }^{12 \mathrm{wl}}$

Counterintuitively, rather than improving sexual health, sex behaviour interventions can make it worse. ${ }^{\text {w2 }}$ Most studies on sex education programmes in schools examine intermediate outcomes only, such as pupil satisfaction or reported condom use. This often facilitates premature false claims of success, whereas more robust outcome measures such as rates of terminations, unplanned conceptions, and sexually transmitted infections show no benefit.

In this week's $B M J$ Henderson and colleagues report the effect of a theoretically based teacher delivered sex education programme (SHARE) on registered conceptions and terminations. ${ }^{3}$ The trial found no significant difference between the intervention and control groups in National Health Service registered conceptions (per 1000 pupils: 300 SHARE $v 274$ control; difference 26, $95 \%$ confidence interval -33 to 86 ) or terminations (127 SHARE $v 112$ control; difference 15, -13 to 42) between ages 16 and 20 .

The results should stimulate urgently needed change from previous ineffective approaches to school sex education for which, as the authors admit, "evidence of effectiveness is mixed." Evidence shows that increased knowledge is a necessary but insufficient cause of change in sexual behaviour. ${ }^{\text {w3 }}$ It is also clear that strategies such as promoting availability and correct use of condoms and increasing use of the emergency pill do not necessarily lead to a reduction in sexually transmitted disease rates, ${ }^{1}$ pregnancies, ${ }^{\mathrm{w} 4}$ or terminations. ${ }^{4}$

So what needs to happen next? Henderson and colleagues stress the need for more comprehensive approaches that incorporate the influence of parents on sexual experience in teenagers, and to improve the future life opportunities for vulnerable young people. The false assumption that "young teens will have sex anyway" is an insult to many young people who have the capacity to rise to a far more effective challenge than just "use a condom every time."

Delaying first intercourse is recognised as an important outcome measure of sex education programmes, and teenagers are more likely to save sex (a more positive and helpful term than "abstinence") when their parents communicate the importance of doing so. ${ }^{5}$ Of course, to be involved in this way, parents have to be with their children. ${ }^{\mathrm{w} 5}$ Much evidence points to the effectiveness of maternal involvement in sex education. ${ }^{6}$ However, the presence of a father is also an important factor in teenagers saving sex until adulthood. ${ }^{\mathrm{w} 6}$ In the Netherlands, many more mothers and fathers talk with their children about sex than in the UK. ${ }^{7}$ The lower rate of single parenthood in the Netherlands is an important factor in the lower rate of teenage pregnancy seen in that country. ${ }^{7}$

Giving students homework to complete with their parents greatly enhanced the effectiveness of one school based abstinence only programme. ${ }^{8}$ This study, however, measured the usual intermediate outcomes only, such as self efficacy and intention to have sex, and more randomised controlled trials of abstinence programmes are needed to look at effects on sexual debut, unplanned conceptions, and sexually transmitted infections.

Much teenage sex has little to do with sex itself but is connected with searching for meaning, identity, and belonging. ${ }^{\text {w7 }}$ These wider sociocultural aspects influencing sexual behaviour need greater attention. ${ }^{9}$ Their importance is highlighted by a Seattle community based programme for children up to age 12, designed to help avoid health risk behaviours in later adolescence. Though good social decision making (including abstaining) in areas such as conflict resolution or drug use was encouraged, this programme contained no specific sex education. Nevertheless, at nine year follow-up, people in the programme were significantly older at first sexual experience and were significantly less likely to become pregnant by age $21(38 \% v 56 \% ; \mathrm{P}<0.05,95 \%$ confidence interval 0.27 to 0.93$).{ }^{10} \mathrm{~A}$ key factor in the Ugandan success in reducing HIV rates so dramatically during the 1990s was a community wide, mass media communication of messages to achieve the desired outcomes of abstinence and being faithful, in addition to condom use. ${ }^{\text {w8 }}$ w9

Blanket assertions that abstinence programmes "don't work" abound. ${ }^{\text {w10 }}$ Ironically, however, the only randomised trial of school sex education identified by the SHARE team to use clinical data on pregnancies was of an abstinence only programme that resulted in a significant reduction of pregnancies. ${ }^{11}$ With the introduction of its recent "Leave it till later" campaign, the UK government is belatedly recognising that saved sex is a vital component of truly safer sex. In the United States, teenage pregnancies are at their lowest level in more than 30 years, and the teenage abortion rate has been halved since its peak in 1988. The only peer reviewed studies of reasons for these trends published up to 2006 attribute two thirds of the teen pregnancy reduction in unmarried 
teenage girls ${ }^{\mathrm{w} 11}$ and just over half of the total reduction to delayed first sex. ${ }^{12}$ With a recent study showing that education to save sex does not lead to decreased condom use at first sex, ${ }^{\text {w12 }}$ it is time the evaluation of saved sex programmes had a share of UK funding for sex education research. However, if saving sex is seen as a way for young people to avoid unplanned pregnancy more than just an educational structure, then last week's government announcement of plans to raise the school leaving age to 18 should do more to reduce teenage pregnancy rates than anything they have done so far. ${ }^{\text {w13 }}$

1. Paton D. Random behaviour or rational choice? Family planning, teenage pregnancy and sexually transmitted infections. SexEducation 2006;6:281-308.

2. Wilkinson P, French R, Kane R, Lachowycz K, Stephenson J, Grundy C, et al Teenage conceptions, abortions, and births in England, 1994-2003, and the national teenage pregnancy strategy. Lancet 2006;368:187986.

3. Henderson M, Wight D, Raab GM, Abraham C, Parkes A, Scott S, et al. Impact of a theoretically based sex education programme (SHARE) delivered by teachers on NHS registered conceptions and terminations: final results of cluster randomised trial. BM/ 2007;334:132-6. doi: $10.1136 /$ bmj. 39014.503692 .55$.

4. Glasier A. Emergency contraception. BMJ 2006;333:560-1.

5. Dilorio C, Kelley M, Hochenberry-Eaton M. Communication about sexual issues: mothers, fathers and friends. J Adolesc Health 1999;24:181-9.

6. McNeely C, Shew ML, Beuhring T, Sieving R, Miller BC, Blum RW. Mother's influence on the timing of first sex among 14 and 15 year-olds. JAdolesc Health 2002;31:256-65.

7. Social Exclusion Unit. Teenage pregnancy. June 1999. www. socialexclusion.gov.uk/downloaddoc.asp?id $=69$.

8. Blake S Simkin S, Ledsky, Perkins C, Calabrese JM. Effects of parentchild communications intervention on young adolescents' risk for early sexual intercourse. Fam Plan Persp 2001;33:52-61.

9. Joseph Roundtree Foundation. "Planned" teenage pregnancy. 2006 www.jrf.org.uk/bookshop/eBooks/9781861348753.pdf.

10. Lonczak H, Abbott R Hawkins D, Kosterman R, Catalano RF. Effects of the Seattle social development project on sexual behaviour, pregnancy, birth and sexually transmitted disease outcomes by age 21yrs. Arch Pediatr Adolesc Med 2002;156:438-47.

11. Cabezon C, Vigil P, Rojas I, Leiva ME, Riquelme R, Aranda W, et al Adolescent pregnancy prevention: an abstinence-centred randomized controlled intervention in a Chilean public high school. J Adolesc Health 2005;36:64-9.

12. Santelli JS, Abma J, Ventura, Lindberg L, Morrow B, Anderson JE, et al. Can changes in sexual behaviors among high school students explain the decline in teen pregnancy rates in the 1990s? JAdolesc Health 2004;35:80-90.

\section{Childhood iron and zinc deficiency in resource poor countries

\author{
Fortification is beneficial, but the best strategy for delivery is unclear
}

\section{RESEARCH p140}

\section{Zulfiqar A Bhutta}

Husein Lalji Dewraj professor and chairman

Department of Paediatrics and Child Health, Aga Khan University, Karachi 74800, Pakistan

zulfiqar.bhutta@aku.edu

Competing interests: None declared

BMJ 2007;334:104-5

doi: $10.1136 /$ bmj.39094.513924.BE
In this week's BMJSazawal and colleagues report a trial of milk fortified with multiple micronutrients (as a strategy to deliver zinc and iron) in children in India. ${ }^{1}$ They found a significant reduction in severe illness and the incidence of acute respiratory infections and diarrhoea. Although data on the impact of the intervention on iron and zinc status are not presented, the functional benefits are consistent with the previously recognised benefits of zinc supplementation on the burden and severity of diarrhoeal diseases and respiratory infections. ${ }^{2}$

Iron deficiency ranked ninth among 26 risk factors included in the global burden of disease study, and accounted for 841000 deaths and 35057000 disability adjusted life years lost. ${ }^{3}$ Large sections of populations in Africa and Asia are at risk of dietary zinc deficiency and resulting high rates of stunting. ${ }^{4}$ Correcting micronutrient deficiencies can help reduce child mortality, ${ }^{5}$ but it is unclear how these deficiencies can be dealt with at the population level. Although combinations of iron and zinc have been suggested as appropriate strategies for rectifying deficiencies of multiple micronutrients in children at risk, the benefits may not be additive because of potential interactions. ${ }^{6}$

Despite promotion of micronutrient supplements, ${ }^{7}$ evidence from many supplementation trials in children is mixed. Some trials using dispersible tablets containing multiple micronutrients have found no significant benefits on functional outcomes. ${ }^{8}$ One study in children in Peru with persistent diarrhoea found higher rates of diarrhoea, respiratory infections, and febrile episodes in the children who received multiple micronutrients and zinc compared with those given zinc supplementation alone. ${ }^{9}$ However, in Karachi daily micronutrient and zinc supplementation reduced rates of diarrhoea. ${ }^{10}$ The findings from a recent large scale trial of iron and zinc supplementation in a malaria endemic area in Zanzibar are more worrying. ${ }^{11}$ In this trial, which compared daily iron and folic acid with iron and folic acid and additional zinc or placebo in infants, the iron and folic acid supplementation arms were stopped early because of a significantly higher rate of mortality and hospital admission.

These data have raised concerns about the safety of large scale iron supplementation programmes in malaria endemic areas, and highlighted the need for alternative strategies to deal with deficiencies in iron and other micronutrients in children at risk. These include fortification of commonly consumed foods, condiments, and staples such as wheat flour. These may be useful for adults, but because of the limited consumption of some of these foods by young infants and children, they may not be the most effective means of delivering recommended amounts of micronutrients.

An alternative strategy might be to fortify commonly consumed centrally processed complementary or weaning foods. However, the availability and cost of such foods in developing countries precludes their widespread use. Alternative strategies include the addition of microencapsulated forms of iron and other micronutrients in the form of "sprinkles" (sachets of fortified powder) to commonly used foods available at home. ${ }^{12}$ Although sprinkles are generally added to foods, much effort may be needed to induce behaviour change and to monitor changes.

Fortification of commonly used food items for children, such as milk, offers an attractive alternative. Sazawal and colleagues' ${ }^{1}$ finding of the acceptability of fortified milk as a delivery vehicle are supported by similar findings from Mexico. ${ }^{13}$ In the Mexican study 
milk fortified with ferrous gluconate and zinc oxide reduced anaemia and iron deficiency.

Notwithstanding the benefits, milk fortification is expensive, and central processing and commodity costs are high. The usefulness, cost effectiveness, and sustainability of this approach must be evaluated at scale in representative populations. A few examples are available of efforts to improve complementary feeding practices as a way of increasing micronutrient intake. The remarkable benefits on growth seen in Peru after a nutrition and health education intervention delivered by the health system suggest that this may be feasible in communities where food availability and choice are not a problem. ${ }^{14}$ However, this approach may not work in places like India, where poverty and religious beliefs preclude adequate intake of micronutrient containing foods such as meat and poultry products. If the availability of food can be ensured through appropriate financial support and social insurance schemes, these interventions are the most logical way to provide iron and zinc to young children.

Availability of fortified milk poses a risk to programmes for the support of exclusive breastfeeding in such countries, so their use and promotion must be strictly targeted and monitored. There is therefore a pressing need to evaluate such interventions in large scale community studies before they can be recommended.

1 Sazawal S, Dhingra U, Hiremath G, Kumar J, Dhingra P, Sarkar A, et al. Effects of fortified milk on morbidity in young children in north India: community based, randomised, double masked placebo controlled trial. BMJ 2007; 334: 140-2. doi: 140-2./10.1136/ bmj.39035.482396.55.

2 Bhutta ZA, Black RE, Brown KH, Gardner JM, Gore S, Hidayat A, et al. Prevention of diarrhea and pneumonia by zinc supplementation in children in developing countries: pooled analysis of randomized controlled trials. Zinc Investigators' Collaborative Group. J Pediatr 1999;135:689-97.

3 Stoltzfus RI. Iron deficiency: global prevalence and consequences. Food Nutr Bull 2003;24(suppl 4):S99-103.

4 International Zinc Nutrition Consultative Group (IZiNCG). Assessment of the risk of zinc deficiency in populations. Food Nutr Bull 2004;25: S130-62.

5 Jones G, Steketee RW, Black RE, Bhutta ZA, Morris SS; Bellagio Child Survival Study Group. How many child deaths can we prevent this year? Lancet 2003;362:65-71.

6 Fischer Walker C, Kordas K, Stoltzfus RJ, Black RE. Interactive effects of iron and zinc on biochemical and functional outcomes in supplementation trials. Am J Clin Nutr 2005;82:5-12.

7 Shrimpton R, Shrimpton R, Schultink W. Can supplements help meet the micronutrient needs of the developing world? Proc Nutr Soc 2002;61:223-9.

8 Smuts CM, Lombard CJ, Benade AJ, Dhansay MA, Berger J, Hop le T, et al; International Research on Infant Supplementation (IRIS) Study Group. Efficacy of a foodlet-based multiple micronutrient supplement for preventing growth faltering, anemia, and micronutrient deficiency of infants: the four country IRIS trial pooled data analysis. J Nutr 2005;135:631S-8S

9 Penny ME, Marin RM, Duran A, Peerson JM, Lanata CF, Lonnerdal B, et al. Randomized controlled trial of the effect of daily supplementation with zinc or multiple micronutrients on the morbidity, growth, and micronutrient status of young Peruvian children. Am J Clin Nutr 2004;79:457-65.

10 SharieffW, Bhutta Z, Schauer C, Tomlinson G, Zlotkin S. Micronutrients (including zinc) reduce diarrhoea in children: the Pakistan sprinkles diarrhoea study. Arch Dis Child 2006;91:573-9.

11 Sazawal S, Black RE, Ramsan M, Chwaya HM, Stoltzfus RJ, Dutta A, et al. Effects of routine prophylactic supplementation with iron and folic acid on admission to hospital and mortality in preschool children in a high malaria transmission setting: community-based, randomised, placebo-controlled trial. Lancet 2006;367:133-43.

12 Zlotkin S, Antwi KY, Schauer C, Yeung G. Use of microencapsulated iron (II) fumarate sprinkles to prevent recurrence of anaemia in infants and young children at high risk. Bull World Health Organ 2003;81:108-15.

13 Villalpando S, Shamah T, Rivera JA, Lara Y, Monterrubio E. Fortifying milk with ferrous gluconate and zinc oxide in a public nutrition program reduced the prevalence of anemia in toddlers. J Nutr 2006;136:2633-7.

14 Penny ME, Creed-Kanashiro HM, Robert RC, Narro MR, Caulfield LE, Black RE. Effectiveness of an educational intervention delivered through the health services to improve nutrition in young children: a

\section{Tuberculosis in resource poor countries Better access to antiretroviral therapy and isoniazid prophylaxis offer new
opportunities for control}

RESEARCH p136

Robert Colebunders

head

HIV/STD Unit, Clinical Sciences

Department, Institute of

Tropical Medicine

2000 Antwerp, Belgium

bcoleb@itg.be

Ludwig Apers

clinician

Epidemiology Unit,

Public Health Department,

Institute of Tropical Medicine

Greet Dieltiens

epidemiologist

William Worodria

clinician

HIV/STD Unit, Clinical Sciences

Department,

Infectious Diseases Institute,

Kampala, Uganda

Competing interests: None declared

BMJ 2007;334:105-6

doi: 10.1136/bmj.39092.388796.80
In most countries with limited resources the epidemics of HIV and tuberculosis continue to grow. ${ }^{1}$ Even with optimal treatment of active tuberculosis, the absolute number of tuberculosis cases will continue to rise if the HIV epidemic is not controlled. ${ }^{1}$ In this week's BMJ, Zar and colleagues report a randomised controlled trial performed in South Africa on the effect of isoniazid prophylaxis on mortality and the incidence of tuberculosis in children infected with HIV. ${ }^{2}$ The results of this study suggest that isoniazid prophylaxis may be an effective public health intervention to reduce mortality in HIV infected children in settings with a high prevalence of tuberculosis. ${ }^{2}$

Today, antiretroviral therapy programmes also offer new opportunities to control tuberculosis..$^{3-5}$ Highly active antiretroviral therapy was shown to decrease the incidence of tuberculosis in HIV positive people by $70 \%$ in South Africa ${ }^{4}$ and $80 \%$ in Brazil. ${ }^{5}$ Although antiretroviral therapy is likely to reduce the incidence of tuberculosis in people infected with HIV, mathemati- cal models have suggested it has limited potential to reduce the burden of tuberculosis within the general population. ${ }^{3}$ However, these models did not take into account the potential effect of antiretroviral therapy on the health seeking behaviour of populations with a high seroprevalence of HIV.

Better access to antiretroviral therapy makes people more willing to be tested for HIV. ${ }^{6}$ This has resulted in a greater awareness of HIV and a reduction in the stigma associated with the disease. ${ }^{7}$ Moreover, voluntary counselling and testing sites are suitable places to screen for tuberculosis and initiate tuberculosis chemoprophylaxis. $^{8}$

HIV seropositive adults with no clinical evidence of tuberculosis benefit from isoniazid prophylaxis..$^{9}$ This protection is less effective in tuberculin skin negative patients, probably not because they are not latently infected with tuberculosis, but because they have such serious cellular immunodeficiency that even chemoprophylaxis cannot protect them. The study by Zar and 
colleagues shows that isoniazid prophylaxis in children (most of whom were not taking antiretroviral therapy) reduced mortality compared with placebo (median follow-up 5.7 months: $11(8.3 \%) v 21(16 \%)$; hazard ratio $0.46,95 \%$ confidence interval 0.22 to 0.95 ) and reduced the incidence of tuberculosis. Antiretroviral therapy reactivates the immune system and therefore may increase the protective effect of tuberculosis chemoprophylaxis. A study in Brazil showed that a combination of highly active antiretroviral therapy and isoniazid prophylaxis reduced the incidence of tuberculosis to 0.6 per 100 person years of follow-up. ${ }^{10}$

Effective case finding and treatment are crucial to controlling tuberculosis. However, in most instances the diagnosis of tuberculosis in people with HIV is delayed, which may foster its transmission in the community. Many factors contribute to this delay such as insufficient awareness about tuberculosis, stigma associated with tuberculosis and HIV, insufficient access to good health care, lack of confidence in healthcare services, and difficulties in diagnosing tuberculosis, particularly in people with HIV. Increased access to antiretroviral therapy could positively influence some of these factors. Indeed, in many countries where free antiretroviral therapy is available, treatment centres are overwhelmed by patients. Moreover in countries with a high seroprevalence of HIV and increasing access to antiretroviral therapy, community efforts to fight both $\mathrm{HIV}$ and tuberculosis are growing.

Before initiating antiretroviral therapy patients should be evaluated for signs or symptoms of tuberculosis. If tuberculosis is diagnosed, treatment for the disease should probably be started before initiating antiretroviral therapy, as this would decrease the risk of the tuberculosis immune reactivation inflammatory syndrome. ${ }^{11}$ Thus, an increase in the capacity to diagnose tuberculosis is needed for the successful implementation of antiretroviral therapy.

In countries with limited resources, antiretroviral therapy is usually not started until patients have advanced HIV disease. Consequently, many people with HIV already have tuberculosis. For example, at the Infectious Diseases Institute in Kampala, Uganda, the mean CD4 lymphocyte count of patients starting antiretroviral therapy is $65 \times 10^{6} / 1$ and $14 \%$ of these patients have a history of tuberculosis. ${ }^{12}$ With increasing access to antiretroviral therapy, more asymptomatic patients with HIV may have access to such treatment. To facilitate early antiretroviral therapy, CD4 lymphocyte counting should be available wherever HIV testing is performed.

Decentralising CD4 lymphocyte counting will lead to earlier initiation of antiretroviral therapy. This will decrease the risk of patients developing tuberculosis and potentially reduce the incidence of tuberculosis in communities where HIV and tuberculosis are prevalent. However, this decentralisation will require extra staff, including qualified nurses and counsellors, and even lay counsellors if not enough health staff are available.

As a way of achieving this objective the World Health Organization developed the integrated management of adolescent and adult illnesses (IMAI) guidelines and IMAI training modules. ${ }^{13}$ These are currently implemented in a growing number of settings, such as Uganda and Senegal, which will report back on their effectiveness in operational circumstances.

Antiretroviral therapy programmes could also favour the transmission of tuberculosis. Firstly, nosocomial transmission of tuberculosis could occur, especially in large scale and centralised HIV treatment centres that lack proper preventative measures. Secondly, the total number of people living with HIV and at increased risk for developing tuberculosis in the region will increase. Finally, if patients do not adhere to their treatment, if inappropriate retroviral regimens are used, or if a reliable supply of antiretroviral therapy is not maintained some patients may remain severely immunodeficient and susceptible to developing tuberculosis and drug resistance.

The increased access to antiretroviral therapy in resource poor settings offers important opportunities for controlling tuberculosis. Access to antiretroviral therapy seems to be changing the health seeking behaviour of the population. This could lead to earlier diagnosis and treatment of HIV and tuberculosis. Collaboration between those implementing HIV and tuberculosis control programmes, needed to scale up the implementation of antiretroviral therapy, will hopefully lead to the strengthening of the healthcare infrastructure in general.

1 Currie CS, Williams BG, Cheng RC, Dye C. Tuberculosis epidemics driven by HIV: is prevention better than cure? AIDS 2003;17:2501-8.

2 Zar HJ, Cotton MF, Strauss S, Karpakis J, Hussey G, Schaaf HS, et al. Effect of isoniazid prophylaxis on mortality and incidence of tuberculosis in children with HIV: randomised controlled trial. BM 2007; 334:136-9. doi: 10.1136/bmj.39000.486400.55.

3 Currie CS, Floyd K, Williams BG, Dye C. Cost, affordability and costeffectiveness of strategies to control tuberculosis in countries with high HIV prevalence. BMC Public Health 2005;5:130.

4 Badri M, Wilson D, Wood R. Effect of highly active antiretroviral therapy on incidence of tuberculosis in South Africa: a cohort study. Lancet 2002;359:2059-64.

5 Santoro-Lopes G, de Pinho AM, Harrison LH, Schechter M. Reduced risk of TB among Brazilian patients with advanced HIV infection treated with HAART. Clin Infect Dis 2002;34:543-6.

6 Wanyenze R, Kamya M, Liechty CA, Ronald A, Guzman DJ, WabwireMangen F, et al. HIV counseling and testing practices at an urban hospital in Kampala, Uganda. AIDS Behav 2006;10:361-7.

7 Levy NC, Miksad RA, Fein OT. From treatment to prevention: the interplay between HIV/AIDS treatment availability and HIV/AIDS prevention programming in Khayelitsha, South Africa.J Urban Health 2005;82:498-509.

8 Wambua N, Odhiambo J, Njoroge A, Chakaya JM, De Cock KM. Implementing measures to reduce the burden of HIV/TB in dually infected patients in a Nairobi slum [abstract]. 14th international conference on HIV/AIDS and sexually transmitted infections in Africa (ICASA). Abuja, Nigeria 2005: ThPoC00416.

9 WHO global tuberculosis programme/UNAIDS. Policy statement on preventive therapy against tuberculosis in people living with HIV. 1998; Document WHO/TB/98.255; UNAIDS/98.34. www.eldis.org/ static/DOC7104.htm.

10 Golub JE, Saraceni V, Cavalcante S, Pacheco AG, King B, Moore RD, et al. Tuberculosis (TB) incidence by HAART and isoniazid prophylactic therapy (IPT) in HIV-infected patients in Rio de Janeiro, Brazil [abstract]. XVI international AIDS conference, 13-16 August 2006: MOPE0395.

11 Narita M, Ashkin D, Hollender ES, Pitchenik AE. Paradoxical worsening of tuberculosis following antiretroviral therapy in patients with AIDS. Am J Respir Crit Care Med 1998;158:157-61.

12 John L, Baalwa J, Kalimugogo P, Nabankema E, Castelnuovo B, Muhindo G, Colebunders R, Kambugu A. Response to 'Does immune reconstitution promote active tuberculosis in patients receiving highly active antiretroviral therapy?' AIDS. 2005 Nov 18;19(17):2049-2050.

13 WHO. Briefing package. Integrated approaches to HIV care, ART and prevention: IMAl and IMCl tools. Geneva: WHO. www.who.int/3by5/ publications/documents/imai/en/. 


\section{PRACTICE p148}

\section{Christopher M Wood}

clinical director and consultant ophthalmologist

Eye Infirmary, Sunderland SR2 9HP

Chris.wood@chs.northy.nhs.uk

Competing interests: None declared

BMJ 2007:334:107

doi: 10.1136/bmj.39093.388900.80

\section{Surgery for cataract}

\section{Reorganisation of in-house services is an efficient way to improve quality and increase volume}

Cataract is the most common cause of visual impairment throughout the world. ${ }^{1}$ In the United Kingdom the prevalence of visually significant cataract is 30\% in people over the age of $65 .^{2}$ Modern cataract surgery rapidly improves vision, can be performed as a day case procedure, and has a low rate of complications. The demand for cataract surgery in the UK exceeds its availability, and the best way to organise services to meet the demand is unclear. In this week's $B M J$ a study by Tey and colleagues reports on how reorganisation of their existing National Health Service ophthalmic service increased the quality and volume of cataract surgery. ${ }^{3}$

The demand for cataract operations has increased, and the number of procedures performed annually in the UK increased by $50 \%$ between 1990 and $1997 .{ }^{4}$ However, the rate of cataract surgery for older people in the UK remained disproportionately low. In 1997 it was still fewer than 2000 per 100000 for over 65 year olds compared with a government target of 3200 per 100 000, and waiting times were longer than 200 days. ${ }^{5}$ The government responded to the deficit by increasing funding for cataract surgery. ${ }^{4}$ The main aims were to improve referral to secondary care, reduce the number of patient visits before and after surgery, and encourage development of efficient, high volume, cataract only operating lists. Cataract surgery would be performed not only in general ophthalmic operating theatres, but also in cataract treatment centres that could be part of the normal local ophthalmic service or in the independent sector. By 2003 annual targets for cataract operations were exceeded, ${ }^{6}$ and by 2005 the maximum wait for surgery was less than three months for all age groups. ${ }^{67}$

Despite these promising results the role of the independent sector, specifically the contribution of independent sector treatment centres in increasing capacity, has been questioned. A report by the House of Commons Heath Committee concluded that they were poorly integrated into the NHS, and that the decision to go ahead with phase one of the independent sector treatment centre programme was "a leap into the dark."

An independent sector treatment centre operating in an area with no capacity problem is a prime example of poor integration. It may result in little or no reduction in the waiting time for cataract surgery at the expense of financial destabilisation of local NHS hospitals. ${ }^{8}$ Also, there will be a loss of training opportunities for junior doctors in the long term, which may lead to a shortage of appropriately trained surgeons. ${ }^{9}$

Separating elective and emergency care does have benefits. For hospital cataract services, much can be gained from having an in-house treatment centre, where only cataract operations are performed. ${ }^{3}{ }^{10}$ The study of Tey and colleagues describes such a model, which has improved the efficiency and quality of care and increased training opportunities for junior ophthalmologists. ${ }^{9}$ This model can be set up at relatively low cost, it increases throughput, and more importantly it is fully integrated with the local service. ${ }^{9}$ Long term results from a similar treatment centre show that the effect can be maintained, with rates of access to cataract surgery among the highest in the country. ${ }^{10}{ }^{11}$ During the past three years the number of people having cataract surgery has stabilised in England and Wales and waiting times have shortened-median waiting times are around 70 days. ${ }^{6}$ Currently $95 \%$ of UK cataract procedures are still performed in (NHS) hospitals, but should more cases be performed in treatment centres?7 ${ }^{7}$ Similar problems with cataract surgery waiting times occurred in Canada, and were resolved by using high volume cataract centres. Waiting times have reduced but there are concerns that this may be at the expense of funding for other ophthalmic treatments, and ultimately there will be excessive unused capacity. ${ }^{12}$

The study by Tey and colleagues suggests that treatment centres within hospitals provide value for money and can deal with the surgical backlogs efficiently and effectively. However, the UK government is keen to extend patient choice and increase the number of independent treatment centres. Independent sector treatment centres certainly have a role in improving access to all forms of surgery, but only if they can integrate into local services and take into account local needs.

1 Thylefors B, Negrel A-D, Pararajasearam R, Dadzie K. Global data on blindness. Bull World Health Organ 1995;73:115-21.

2 Reidy A, Minassian DC, Vafidis G, Joseph J, Farrow S, Wu J, et al. Prevalence of serious eye disease and visual impairment in a north London population: population-based, cross sectional study. BMJ 1998;316:1643-6.

3 Tey A, Grant B, Harbison D, Sutherland S, Kearns P, Sanders R. Redesign and modernisation of an NHS cataract service (Fife 1997-2004): multifaceted approach. BMJ 2007;334:148-52. doi: 10.1136/ bmj.39050.520069.BE.

4 Department of Health. Action on cataracts: good practice guidance. London: DOH, 2000. www.dh.gov.uk/ assetRoot/04/01/45/14/04014514.pdf.

5 Department of Health. NHS drive to end long waits for eye operations. Press release. London: DOH, 2003. www.dh.gov.uk/ PublicationsAndStatistics/PressReleases/PressReleasesNotices/fs/ en?CONTENT_ID=4046841\&chk=j\%2B1XKd.

6 Department of Health. Hospital activity and episode statistics. London: DOH. www.dh.gov.uk/PublicationsAndStatistics/Statistics/ HospitalEpisodeStatistics/fs/en.

7 Department of Health. Faster access and more choice for cataract patients. Press release. London: DOH, 2005. www.dh.gov.uk/ PublicationsAndStatistics/PressReleases/PressReleasesNotices/fs/ en?CONTENT ID =4102616\&chk=fMQsuJ.

8 House of Commons Health Committee. Independent sector treatment centres. Fourth report of session 2005-6. Vol. 1. www.publications. parliament.uk/pa/cm200506/cmselect/cmhealth/934/934i.pdf.

9 Au L, Saha K, Fernando B, Ataullah S, Spencer F. "Fast track” cataract services and diagnostic and treatment centre: impact on surgical training. Eye 14 Jul 2004 [Epub ahead of print].

10 Cresswell PA, Allen ED, Tomkinson J, Chapman FM, Pickering S, Donaldson LJ. Cost effectiveness of a single function treatment center for cataract surgery. J Cataract Refract Surg 1996;22:940-6.

11 Bailey K, Deane M, MacKnight N, Chappel D, Wilkinson J. Cataract surgery in the North East of England. North East Public Health Observatory. Paper 04, 2004. www.nepho.org.uk/index.php?c=634. 12 Bellan L. Cataract surgery in Canada. Can J Ophthalmol 2004;41:539-41. 


\section{Renaming schizophrenia \\ Diagnosis and treatment are more important than semantics}

\begin{abstract}
Jeffrey A Lieberman
chairman and director

jlieberman@columbia.edu

Michael B First

professor of clinical psychiatry

Department of Psychiatry, Columbia

University College of Physicians

and Surgeons, New York State

Psychiatric Institute, New York, NY

10032, USA

Competing interests: JAL receives

research grant support from

Acadia, Bristol-Myers Squibb,

GlaxoSmithKline, Merck, Organon,

and Pfizer. MBF has received

consultant fees from AstraZeneca,

Abbott Laboratories, and

GlaxoSmithKline and has been an

expert witness regarding diagnosis

of schizophrenia
\end{abstract}

BMJ 2007;334:108

doi=10.1136/bmj.39057.662373.80
Recent reports in the media have called for schizophrenia to be "abolished as a concept" because it is scientifically meaningless. ${ }^{1}$ This is not the first time that the validity of this diagnostic entity has been challenged, and it will not be the last until the cause of the disorder and its precise pathophysiology are known.

The current system of psychiatric diagnosis cannot describe definitive disease entities because of our inability to demonstrate "natural" boundaries between disorders. However, as Kendell and Jablensky point out, "thoughtful clinicians have long been aware that diagnostic categories are simply concepts, justified only by whether they provide a useful framework for organising and explaining the complexity of clinical experience in order to derive inferences about outcome and to guide decisions about treatment." In this context, the charge that schizophrenia does not define a specific illness is clearly unwarranted. Although the validity of the diagnosis remains to be established, its diagnostic reliability and usefulness are indisputable.

For more than 100 years schizophrenia has been an integral part of our nosology and has facilitated research and treatment of people affected by this disease. ${ }^{34}$ People qualify for the diagnosis if their clinical signs and symptoms conform to the operational diagnostic criteria that define schizophrenia. Many studies have shown that these diagnostic criteria can be applied reliably and accurately by trained mental health professionals. ${ }^{56}$ Although a diagnosis of schizophrenia depends on the presence of a pattern of symptoms (such as delusions, hallucinations, disorganised speech, disorganised or catatonic behaviour, and negative symptoms such as lack of motivation), evidence shows that these are manifestations of brain pathology. ${ }^{7}$ Schizophrenia is not caused by disturbed psychological development or bad parenting. Compared with normal controls, people with schizophrenia have abnormalities in brain structure and function seen on neuroimaging and electrophysiological tests. In addition, the evidence that vulnerability to schizophrenia is at least partly genetic is indisputable. ${ }^{8}$

Once a diagnosis of schizophrenia is made, the treating clinician has a wide array of treatment options available, which have been tested empirically on similar groups of people. Furthermore, the doctor will also have access to the huge body of empirical data that characterises this condition including its course, treatment response, outcome, and family history. This is important because evidence shows that early intervention may improve outcome. ${ }^{9}$ The diagnosis also helps when explaining to the patient and their family the nature of the problem, the range of treatments and outcomes, and the assistance available from support groups.

Of course, diagnostic labels have potential disadvantages. If a diagnosis of schizophrenia is mistakenly applied, the patient will receive the wrong treatment and potentially have the stigma of having a mental illness. For example, if a patient with a toxic (such as phencyclidine induced) psychosis is misdiagnosed with schizophrenia, he or she may be given a long and unnecessary course of antipsychotic drugs. To avoid this situation, psychiatric diagnoses have built-in safeguards in the form of exclusion criteria that prevent a diagnosis from being made if certain conditions are present (for example, a diagnosis of schizophrenia is not permitted unless psychotic symptoms persist for a substantial period of time after the person has stopped using the drug in question).

Concerns about potential stigma associated with having a serious mental illness have resulted in proposals to change the name of schizophrenia. "Integration disorder" and "dopamine dysregulation disorder" have been suggested as possible alternatives. ${ }^{10}$ Unfortunately, changing the name of the condition (or even abolishing the concept) will not affect the root cause of the stigma-the public's ignorance and fear of people with mental illness. Renaming may even have the unintended effect that the person, rather than the illness, is blamed for the symptoms. ${ }^{11}$

Ultimately, we must gain a more complete understanding of the causes and pathophysiological mechanisms underlying schizophrenia. Only then can we replace the way we characterise schizophrenia with a diagnosis that more closely conforms to a specific brain disease. In the meantime, we can be confident and grateful that the benefits conferred by the concept of schizophrenia far outweigh any perceived disadvantages.

1 Boseley S. Call to wipe out schizophrenia as catch-all tag. Guardian, 10 October 2006

2 Kendell R, Jablensky A. Distinguishing between the validity and utility of psychiatric diagnoses. Am J Psychiatry 2003;160:4-12.

3 Kraepelin E. Psychiatrie: Ein Lehrbuch für Studirende und Ärzte. 4th ed. (Psychiatry: a textbook for students and physicians. 4th ed.) Leipzig, Germany: Abel, 1893.

4 Bleuler E. Dementia praecox, oder die Gruppe der Schizophrenien. (Dementia praecox, or the group of the schizophrenias.) Leipzig, Germany: Franz Deuticke, 1911.

5 Jakobsen KD, Frederiksen JN, Hansen T, Jansson LB, Parnas J, Werge T. Reliability of clinical ICD-10 schizophrenia diagnoses. Nord J Psychiatry 2005;59:209-12.

6 McCormick LM, Flaum M. Diagnosing schizophrenia circa 2005: how and why? Curr Psychiatry Rep 2005;7:311-5.

7 Andreasen N. The broken brain: the biological revolution in psychiatry. New York: Harper and Row, 1984.

8 Lewis DA, Lieberman JA. Catching up on schizophrenia: natural history and neurobiology. Neuron 2000;28:325-34.

9 Perkins DO, Gu H, Boteva K, Lieberman JA. Relationship between duration of untreated psychosis and outcome in first-episode schizophrenia: a critical review and meta-analysis. Am J Psychiatry 2005;162:1785-804.

10 Sugiura T, Sakamoto S, Tanaka E, Tomoda A, Kitamura T. Labelling effect of Selshin-bunretsu-byou, the Japanese translation for schizophrenia: an argument for re-labelling. Int J Soc Psychiatry 2001;47:43-51.

11 Penn DL, Nowlin-Drummond A. Politically correct labels and schizophrenia. A rose by any other name? Schizophrenia Bull 2001;27:197-203. 